\title{
Fixed Point Theorem in Fuzzy Metric Space
}

\author{
Manoj Kumar Tiwari, \\ Deptt. of Mathematics, Pt. Sundarlal Sharma (Open ) University, \\ Chhattisgarh, Bilaspur.
}

\begin{abstract}
In this research paper we have established a common fixed point theorem for compatible pair of self mappings in a fuzzy metric space. 2000 Mathematics Subject Classification: 54H25, 47H10.
\end{abstract}

Key Words and phrases: Common fixed point, Fuzzy metric space, compatible maps.

\section{INTRODUCTION}

The concept of fuzzy sets was initiated by L.A. Zadeh [19] in 1965 and the concept of fuzzy metric space was introduced by Kramosil and Michalek [9]. Grabiec [5] proved the contraction principle in the setting of the fuzzy metric space which was further generalization of results by Subrahmanyam [17] for a pair of commuting mappings. George and Veeramani [4] have modified the notion of fuzzy metric spaces with the help of continuous t-norm, by generalizing the concept of probabilistic metric space to fuzzy situation. Also, Jungck and Rhoades [7] defined a pair of self mappings to be weakly compatible if they commute at their coincidence points. Balasubramaniam et.al. [1] proved a fixed point theorem, which generalizes a result of Pant for fuzzy mappings in fuzzy metric space.Also, Jha et.al.[6] have proved a common fixed point theorem for four self maps in fuzzy metric space under the weak contractive conditions. Also, B. Singh and S. Jain [16] introduced the notion of semicompatible mappings in fuzzy metric space and compared this notion with the notion of compatible map of type $(\alpha)$, compatible map of type $(\beta)$ and obtained some fixed point theorems in complete fuzzy metric space in the sense of Grabiec [5]. As a generalization of fixed point results of Singh and Jain [16], Mishra et. al.[10] have proved a fixed point theorems in complete fuzzy metric space by replacing continuity condition with reciprocally continuity maps.

The aim of this paper is to obtain a common fixed point theorem for compatible pair of self mappings in fuzzy metric space.

Now, We have used the following notions:

DEFINITION 1.1([19]) Let $X$ be any set. A fuzzy set $A$ in $X$ is a function with domain $X$ and values in $[0,1]$.

DEFINITION 1.2([4]) A binary operation $*:[0,1] \times[0,1] \rightarrow[0,1]$ is called a continuous t-norm if, $([0,1], *)$ is an abelian topological monoid with unit 1 such that $\mathrm{a} * \mathrm{~b} \leq \mathrm{c} * \mathrm{~d}$ whenever

$\mathrm{a} \leq \mathrm{c}$ and $\mathrm{b} \leq \mathrm{d}$, for all $\mathrm{a}, \mathrm{b}, \mathrm{c}, \mathrm{d}$ in $[0,1]$.

For an example: $a * b=a b, a * b=\min \{a, b\}$.

DEFINITION 1.3([4]) The triplet $(\mathrm{X}, \mathrm{M}, *)$ is called a fuzzy metric space if, $\mathrm{X}$ is an arbitrary set, * is a continuous t-norm and $\mathrm{M}$ is a fuzzy set on $\mathrm{X} \times \mathrm{X} \times[0,1)$ satisfying

the following conditions: for all $x, y, z$ in $\mathrm{X}$, and $\mathrm{s}, \mathrm{t}>0$,

[i] $\mathrm{M}(x, y, 0)=0, \mathrm{M}(x, y, \mathrm{t})>0$;

[ii] $\mathrm{M}(x, y, \mathrm{t})=1$ for all $\mathrm{t}>0$ if and only if $x=y$,

[iii] $\mathrm{M}(x, y, \mathrm{t})=\mathrm{M}(y, x, \mathrm{t})$,

[iv] $\mathrm{M}(x, y, \mathrm{t}) * \mathrm{M}(y, z, \mathrm{~s}) \leq \mathrm{M}(x, z, \mathrm{t}+\mathrm{s})$,

[v] $\mathrm{M}(x, y, \cdot):[0, \infty) \rightarrow[0,1]$ is left continuous.

In this case, $\mathrm{M}$ is called a fuzzy metric on $\mathrm{X}$ and the function $\mathrm{M}(x, y, \mathrm{t})$ denotes the degree of nearness between $x$ and $y$ with respect to $t$.

Also, we consider the following condition in the fuzzy metric space $(\mathrm{X}, \mathrm{M}, *)$ :

[vi] $\operatorname{limt} \rightarrow \infty \mathrm{M}(x, y, \mathrm{t})=1$, for all $x, y \in \mathrm{X}$.

It is important to note that every metric space $(X, d)$ induces a fuzzy metric space $(X, M, *)$ where $a * b=\min \{a, b\}$ and for all $\mathrm{a}, \mathrm{b} \in \mathrm{X}$, we have $M(x, y, t)=\frac{t}{t+d(x, y)}$, for all $\mathrm{t}>0$, and $\mathrm{M}(x, y, 0)=0$, so-called the fuzzy metric space induced by the metric d.

DEFINITION 1.4([4]) In a fuzzy metric space $(X, M, *)$ a sequence $\{x n\}$ is called a Cauchy sequence if, limn $\rightarrow \infty M(x n+p$, $x \mathrm{n}, \mathrm{t})=1$ for every $\mathrm{t}>0$ and for each $\mathrm{p}>0$.

A fuzzy metric space $(X, M, *)$ is complete if, every Cauchy sequence in $\mathrm{X}$ converges in $\mathrm{X}$.

DEFINITION 1.5([4]) In a fuzzy metric space $(\mathrm{X}, \mathrm{M}, *) \mathrm{A}$ sequence $\{x \mathrm{n}\}$ is said to be convergent to $x$ in $\mathrm{X}$ if, limn $\rightarrow \infty \mathrm{M}(x \mathrm{n}$, $x, \mathrm{t})=1$, for each $\mathrm{t}>0$.

It is noted that since $*$ is continuous, it follows from the condition [iv] of Definition (1.3.) that the limit of a sequence in a fuzzy metric space is unique. 
DEFINITION 1.6([1]) Two self mappings A and B of a fuzzy metric space $(\mathrm{X}, \mathrm{M}, *)$ are said to be compatible if, limn $\rightarrow \infty$ $\mathrm{M}(\mathrm{AB} x \mathrm{n}, \mathrm{BA} x \mathrm{n}, \mathrm{t})=1$ whenever $\{x \mathrm{n}\}$ is a sequence such that $\lim \mathrm{n} \rightarrow \infty \mathrm{A} x \mathrm{n}=\lim \mathrm{n} \rightarrow \infty \mathrm{B} x \mathrm{n}=\mathrm{p}$, for some $\mathrm{p}$ in $\mathrm{X}$.

LEMMA 1.11([14]) Let $(\mathrm{X}, \mathrm{M}, *)$ be a fuzzy metric space. If there exists $\mathrm{k} \in(0,1)$ such that $\mathrm{M}(x, y, \mathrm{kt}) \geq \mathrm{M}(x, y, \mathrm{t})$ then $x=y$.

PROPOSITION 1.12: Let $A$ and $B$ be compatible, self mappings of a fuzzy metric space $X$,

(1) If $\mathrm{Ay}=\mathrm{By}$ then $\mathrm{ABy}=\mathrm{Bay}$.

(2) If $\mathrm{A} x \mathrm{n}, \mathrm{B} x \mathrm{n} \rightarrow \mathrm{y}$, for some $\mathrm{y}$ is $\mathrm{X}$ then

(a) BAxn $\rightarrow$ Ay if $\mathrm{A}$ is continuous.

(b) If $\mathrm{A}$ and $\mathrm{B}$ are continuous at $\mathrm{y}$ then $\mathrm{Ay}=\mathrm{By}$ and $\mathrm{ABy}=\mathrm{BAy}$.

PROOF: (1) Let $\mathrm{Ay}=\mathrm{By}$ and $\{\mathrm{xn}\}$ be a sequence in $\mathrm{X}$ such that $\mathrm{xn}=\mathrm{y}$ for all $\mathrm{n}$. Then Axn, B $x \mathrm{n} \rightarrow \mathrm{Ay}$. Now by the compatibility of $\mathrm{A}$ and $\mathrm{B}$, we have

$\mathrm{M}(\mathrm{ABy}, \mathrm{BAy}, \mathrm{t})=\mathrm{M}(\mathrm{AB} x \mathrm{n}, \mathrm{BA} x \mathrm{n}, \mathrm{t})=1$ which yields $\mathrm{ABy}=\mathrm{BAy}$.

(2) If $\mathrm{A} x \mathrm{n}, \mathrm{B} x \mathrm{n} \rightarrow \mathrm{y}$, for some $\mathrm{y}$ is $\mathrm{X}$ then

(a) By the continuity of $\mathrm{A}, \mathrm{ABxn} \rightarrow \mathrm{Ay}$ and by compatibility of $\mathrm{A}, \mathrm{B}$

$\mathrm{M}(\mathrm{AB} x \mathrm{n}, \mathrm{BA} x \mathrm{n}, \mathrm{t})=1$ as $\mathrm{n} \rightarrow \infty$, which yields BAxn $\rightarrow$ Ay.

(b) If $\mathrm{A}$ and B are continuous then from (a) we have BAxn $\rightarrow$ Ay. But by the continuity of B, BAxn $\rightarrow$ By. Thus by uniqueness of the limit $\mathrm{Ay}=\mathrm{By}$. Hence $\mathrm{ABy}=\mathrm{BAy}$ from (1).

\section{MAIN RESULTS}

THEOREM 2.1. Let $(X, M, *)$ be a complete fuzzy metric space with additional condition [vi] and with a $* a \geq a$ for all a $\in[0$, 1]. Let $A, B, S$ and $T$ be mappings from $X$ into itself such that :

[i] $\mathrm{A}(\mathrm{X}) \subseteq \mathrm{T}(\mathrm{X}), \mathrm{B}(\mathrm{X}) \subseteq \mathrm{S}(\mathrm{X})$

[ii] One of the A, B, S or T is continuous,

[iii] $(\mathrm{A}, \mathrm{S})$ and $(\mathrm{B}, \mathrm{T})$ are compatible pairs of mappings,

[iv] $\mathrm{M}(\mathrm{A} x, \mathrm{~B} y, \mathrm{t}) \geq \phi(\min \{\mathrm{M}(\mathrm{Sx}, \mathrm{Ty}, \mathrm{t}), \mathrm{M}(\mathrm{Ax}, \mathrm{Ty}, \alpha \mathrm{t}), \mathrm{M}(\mathrm{Sx}, \mathrm{By},(2-\alpha) \mathrm{t})\}$,$) for all x, y \in \mathrm{X}, \quad \alpha \in(0,2)$ and $\mathrm{t}>0$. where $\phi$ $:[0,1] \rightarrow[0,1]$ is a continuous function such that $\phi(t)>t$ for some $0<t<1$. Then $A, B, S$ and T have a unique common fixed point in $\mathrm{X}$.

PROOF: Let $x 0 \in \mathrm{X}$ be an arbitrary point. Then, since $\mathrm{A}(\mathrm{X}) \subseteq \mathrm{T}(\mathrm{X}), \mathrm{B}(\mathrm{X}) \subseteq \mathrm{S}(\mathrm{X})$, there exists $x 1, x 2 \in \mathrm{X}$ such that $\mathrm{A} x 0=$ $\mathrm{T} x 1$ and $\mathrm{B} x 1=\mathrm{S} x 2$. Inductively, we construct the sequences $\{y \mathrm{n}\}$ and $\{x \mathrm{n}\}$ in $\mathrm{X}$ such that $y 2 \mathrm{n}=\mathrm{A} x 2 \mathrm{n}=\mathrm{T} x 2 \mathrm{n}+1$ and $y 2 \mathrm{n}+1=$ $\mathrm{B} x 2 \mathrm{n}+1=\mathrm{S} x 2 \mathrm{n}+2$, for $\mathrm{n}=0,1,2, \ldots$.

Now, we put $\alpha=1-\mathrm{q}$ with $\mathrm{q} \in(0,1)$ in [iv], we have

$\mathrm{M}(y 2 \mathrm{n}, y 2 \mathrm{n}+1, \mathrm{t})=\mathrm{M}(\mathrm{A} x 2 \mathrm{n}, \mathrm{B} x 2 \mathrm{n}+1, \mathrm{t})$

That is,

$\geq \phi(\min \{\mathrm{M}(\mathrm{S} x 2 \mathrm{n}, \mathrm{T} x 2 \mathrm{n}+1, \mathrm{t}), \mathrm{M}(\mathrm{A} x 2 \mathrm{n}, \mathrm{T} x 2 \mathrm{n}+1,(1-\mathrm{q}) \mathrm{t}), \mathrm{M}(\mathrm{S} x 2 \mathrm{n}, \mathrm{B} x 2 \mathrm{n}+1,(1+\mathrm{q}) \mathrm{t})\})$.

$\mathrm{M}(y 2 \mathrm{n}, y 2 \mathrm{n}+1, \mathrm{t}) \geq \phi(\min \{\mathrm{M}(y 2 \mathrm{n}-1, y 2 \mathrm{n}, \mathrm{t}), \mathrm{M}(y 2 \mathrm{n}, y 2 \mathrm{n}+1, \mathrm{t}), \mathrm{M}(y 2 \mathrm{n}-1, y 2 \mathrm{n}+1,(1+\mathrm{q}) \mathrm{t})\})$

$\geq \phi(\min \{\mathrm{M}(y 2 \mathrm{n}-1, y 2 \mathrm{n}, \mathrm{t}), \mathrm{M}(y 2 \mathrm{n}, y 2 \mathrm{n}+1, \mathrm{t}), \mathrm{M}(y 2 \mathrm{n}-1, y 2 \mathrm{n}, \mathrm{t}), \mathrm{M}(y 2 \mathrm{n}-1, y 2 \mathrm{n}+1, \mathrm{qt})\})$

$\geq \mathrm{M}(y 2 \mathrm{n}-1, y 2 \mathrm{n}, \mathrm{t}) * \mathrm{M}(y 2 \mathrm{n}, y 2 \mathrm{n}+1, \mathrm{t}) * \mathrm{M}(y 2 \mathrm{n}, y 2 \mathrm{n}+1, \mathrm{qt})$.

Since t-norm $*$ is continuous, letting $\mathrm{q} \rightarrow 1$, we have

$\mathrm{M}(y 2 \mathrm{n}, y 2 \mathrm{n}+1, \mathrm{t}) \geq \phi(\min \{\mathrm{M}(y 2 \mathrm{n}-1, y 2 \mathrm{n}, \mathrm{t}), \mathrm{M}(y 2 \mathrm{n}, y 2 \mathrm{n}+1, \mathrm{t}), \mathrm{M}(y 2 \mathrm{n}, y 2 \mathrm{n}+1, \mathrm{t})\}$

$\geq \phi(\min \{\mathrm{M}(y 2 \mathrm{n}-1, y 2 \mathrm{n}, \mathrm{t}), \mathrm{M}(y 2 \mathrm{n}, y 2 \mathrm{n}+1, \mathrm{t})\})$.

It follows that, $\mathrm{M}(y 2 \mathrm{n}, y 2 \mathrm{n}+1, \mathrm{t})>\mathrm{M}(y 2 \mathrm{n}-1, y 2 \mathrm{n}, \mathrm{t})$, since $\phi(\mathrm{t})>\mathrm{t}$ for each $0<\mathrm{t}<1$.

Similarly, $\mathrm{M}(y 2 \mathrm{n}+1, y 2 \mathrm{n}+2, \mathrm{t})>\mathrm{M}(y 2 \mathrm{n}, y 2 \mathrm{n}+1, \mathrm{t})$. Therefore, in general, we have

$\mathrm{M}(y \mathrm{n}, y \mathrm{n}+1, \mathrm{t}) \geq \phi(\mathrm{M}(y \mathrm{n}-1, y \mathrm{n}, \mathrm{t}))>\mathrm{M}(y \mathrm{n}-1, y \mathrm{n}, \mathrm{t})$.

Therefore, $\{\mathrm{M}(y \mathrm{n}, y \mathrm{n}+1, \mathrm{t})\}$ is an increasing sequence of positive real numbers in $[0,1]$ and tends to a limit, say $\lambda \leq 1$. We claim that $\lambda=1$. If $\lambda<1$, then $\mathrm{M}(y \mathrm{n}, y \mathrm{n}+1, \mathrm{t}) \geq \phi\left(\mathrm{M}\left(y_{\mathrm{n}}-1, y \mathrm{n}, \mathrm{t}\right)\right)$.

So, on letting $\mathrm{n} \rightarrow \infty$, we get limn $\rightarrow \infty \mathrm{M}(y \mathrm{n}, y \mathrm{n}+1, \mathrm{t}) \geq \phi(\operatorname{limn} \rightarrow \infty \mathrm{M}(y \mathrm{n}, y \mathrm{n}+1, \mathrm{t}))$

that is, $\lambda \geq \mathrm{r}(\lambda)>\lambda$, a contradiction. Thus, we have $\lambda=1$.

Now, for any positive integer $\mathrm{p}$, we have

$\mathrm{M}(y \mathrm{n}, y \mathrm{n}+\mathrm{p}, \mathrm{t}) \geq \mathrm{M}(y \mathrm{n}, y \mathrm{n}+1, \mathrm{t}) * \mathrm{M}(y \mathrm{n}+1, y \mathrm{n}+2, \mathrm{t} / \mathrm{p}) * \ldots * \mathrm{M}(y \mathrm{n}+\mathrm{p}-1, y \mathrm{n}+\mathrm{p}, \mathrm{t} / \mathrm{p})$.

Letting $\mathrm{n} \rightarrow \infty$, we get limn $\rightarrow \infty \mathrm{M}(y \mathrm{n}, y \mathrm{n}+\mathrm{p}, \mathrm{t}) \geq 1 * 1 * \ldots \ldots * 1=1$.

Thus, we have limn $\rightarrow \infty \mathrm{M}(y \mathrm{n}, y \mathrm{n}+\mathrm{p}, \mathrm{t})=1$. Hence, $\{y \mathrm{n}\}$ is a Cauchy sequence in $\mathrm{X}$. Since $\mathrm{X}$ is complete metric space, so the sequence $\{y n\}$ converges to a point $u$ (say) in $X$ and consequently, the subsequences $\{A x 2 n\},\{S x 2 n\},\{T x 2 n+1\}$ and $\{B x 2 n+1\}$ also converges to $\mathrm{u}$.

We first consider the case when $(\mathrm{A}, \mathrm{S})$ and $(\mathrm{B}, \mathrm{T})$ are compatible mappings. Since $\mathrm{A}$ and $\mathrm{S}$ are compatible maps, so we have $\operatorname{limn} \rightarrow \infty \mathrm{M}(\mathrm{AS} x \mathrm{n}, \mathrm{SA} x \mathrm{n}, \mathrm{t})=1$ whenever $\{x \mathrm{n}\}$ is a sequence such that $\lim \mathrm{n} \rightarrow \infty \mathrm{A} x \mathrm{n}=\lim \mathrm{n} \rightarrow \infty \mathrm{S} x \mathrm{n}=\mathrm{u}$, for some $\mathrm{u}$ in $\mathrm{X}$. Therefore, we get $\mathrm{Au}=\mathrm{Su}$. And also B and T are compatible maps, so we have limn $\rightarrow \infty \mathrm{M}(\mathrm{BT} x \mathrm{n}, \mathrm{TB} x \mathrm{n}, \mathrm{t})=1$ whenever $\{x \mathrm{n}\}$ is a sequence such that $\lim \mathrm{n} \rightarrow \infty \mathrm{B} x \mathrm{n}=\lim \mathrm{n} \rightarrow \infty \mathrm{T} x \mathrm{n}=\mathrm{u}$, for some $\mathrm{u}$ in $\mathrm{X}$.

We claim that $A u=u$. For this, suppose that $A u \neq u$. 
Then, setting $x=\mathrm{u}$ and $\mathrm{y}=x 2 \mathrm{n}+1$ in contractive condition [iv] with $\alpha=1$, we get

$\mathrm{M}(\mathrm{Au}, \mathrm{B} x 2 \mathrm{n}+1, \mathrm{t}) \geq \phi(\min \{\mathrm{M}(\mathrm{Su}, \mathrm{T} x 2 \mathrm{n}+1, \mathrm{t}), \mathrm{M}(\mathrm{Au}, \mathrm{T} x 2 \mathrm{n}+1, \mathrm{t}), \mathrm{M}(\mathrm{Su}, \mathrm{B} x 2 \mathrm{n}+1, \mathrm{t})\})$.

Letting $n \rightarrow \infty$, we get $M(A u, u, t) \geq r(M(A u, u, t))>M(A u, u, t)$, which implies that $u=A u$.

Thus, we have $\mathrm{u}=\mathrm{Au}=\mathrm{Su}$. Since $\mathrm{A}(\mathrm{X}) \subseteq \mathrm{T}(\mathrm{X})$, so there exists $\mathrm{v}$ in $\mathrm{X}$ such that $\mathrm{u}=\mathrm{Au}=\mathrm{Tv}$.

Therefore, setting $x=x 2 \mathrm{n}$ and $\mathrm{y}=\mathrm{v}$ in contractive condition [iv] with $\alpha=1$, we get

$\mathrm{M}(\mathrm{A} x 2 \mathrm{n}, \mathrm{Bv}, \mathrm{t}) \geq \phi(\min \{\mathrm{M}(\mathrm{S} x 2 \mathrm{n}, \mathrm{Tv}, \mathrm{t}), \mathrm{M}(\mathrm{A} x 2 \mathrm{n}, \mathrm{Tv}, \mathrm{t}), \mathrm{M}(\mathrm{S} x 2 \mathrm{n}, \mathrm{Bv}, \mathrm{t})\})$.

Letting $n \rightarrow \infty$, we get $M(A u, B v, t) \geq \phi(M(A u, B v, t))>M(A u, B v, t)$, which implies that $u=B v$.

Thus, we have $u=B v=T v$. Therefore, we get $u=A u=S u=B v=T v$.

Now, since $u=B v=T v$, so by the compatibility of $(B, T)$, it follows that $B T v=T B v$ and so we get $B u=B T v=T B v=T u$.

Thus, from the contractive condition (iv) with $\alpha=1$, we have

$\mathrm{M}(\mathrm{Au}, \mathrm{Bu}, \mathrm{t}) \geq \phi(\min \{\mathrm{M}(\mathrm{Su}, \mathrm{Tu}, \mathrm{t}), \mathrm{M}(\mathrm{Au}, \mathrm{Tu}, \mathrm{t}), \mathrm{M}(\mathrm{Su}, \mathrm{Bu}, \mathrm{t})\})$,

that is, $\mathrm{M}(\mathrm{u}, \mathrm{Bu}, \mathrm{t})>\mathrm{M}(\mathrm{u}, \mathrm{Bu}, \mathrm{t})$, which is a contradiction.

$\Rightarrow \mathrm{u}=\mathrm{Bu}$. Similarly, using condition [iv] with $\alpha=1$, one can show that $\mathrm{Au}=\mathrm{u}$. Therefore, we have $\mathrm{u}=\mathrm{Au}=\mathrm{Bu}=\mathrm{Tu}=$

Su. Hence, the point $u$ is a common fixed point of A, B, S and T.

\section{UNIQUENESS :}

We easily verified the uniqueness of a common fixed point of the mappings $\mathrm{A}, \mathrm{B}, \mathrm{S}$ and $\mathrm{T}$ by using [iv]. In fact, if $\mathrm{u} 0$ be another fixed point for mappings $\mathrm{A}, \mathrm{B}, \mathrm{S}$ and $\mathrm{T}$. Then, for $\alpha=1$, we have $\mathrm{M}(\mathrm{u}, \mathrm{u} 0, \mathrm{t})=\mathrm{M}(\mathrm{Au}, \mathrm{Bu} 0, \mathrm{t}) \geq \phi(\min \{\mathrm{M}(\mathrm{Su}, \mathrm{Tu} 0, \mathrm{t}), \mathrm{M}(\mathrm{Au}, \mathrm{Tu} 0, \mathrm{t}), \mathrm{M}(\mathrm{Su}, \mathrm{Bu} 0, \mathrm{t})\})$,

This completes the proof of the theorem. $\geq \phi(\mathrm{M}(\mathrm{u}, \mathrm{u} 0, \mathrm{t}))>\mathrm{M}(\mathrm{u}, \mathrm{u} 0, \mathrm{t})$, and hence, we get $\mathrm{u}=\mathrm{u} 0$.

\section{REFERENCES}

[1] Balasubramaniam P, Muralishankar S \& Pant R P, Common fixed points of four mappings in a fuzzy metric space, J. Fuzzy Math., 10(2)(2002), 379 .

[2] Cho Y J, Pathak H K, Kang S M \& Jung J S, Common fixed points of compatible mappings of type (B) on on fuzzy metric space, Fuzzy Sets and Systems, 93(1998), 99.

[3] Chauhan M S, Badshah V M, \& Chouhan V S, Common fixed point of semi-compatible maps in fuzzy metric space, Kath. Univ. J. Sci. Engg. Tech., $6(1)(2010), 70$

[4] George A \& Veeramani P, On some results in fuzzy metric space, Fuzzy Sets and Systems, 64(1994), 395.

[5] Grabiec G, Fixed points in fuzzy metric spaces, Fuzzy Sets and Systems, 27(1988), 385.

[6] Jha K, Karadzhov G E \& Pecaric J, A generalized common fixed point in fuzzy metric space, The Nepali Math. Sci. Report, $30(1-2)(2010)$, 62.

[7] Jungck G \& Rhoades B E, Fixed point for set valued functions without continuity, Indian J. Pure Appl. Math., 29(3)(1998), 227.

[8] Khan M S, Pathak H K \& George R, Compatible mappings of Type (A-1) and Type A-2 and common fixed points in fuzzy metric spaces, Int. Math. Forum, 2(2007), 515.

[9] Kramosil O \& Michalek J, Fuzzy metric and statistical metric spaces, Kybernetika, 11(1975), 326.

[10] Mishra U, Ranadive A S and Gopal D, Some fixed points theorems in fuzzy metric space, Tamkang J. Math., 39(4)(2008), 309.

[11] Pant R P \& Jha K, A remark on common fixed points of four mappings in a fuzzy metric space, J. Fuzzy Math., $12(2)(2004), 433$.

[12] Pant V, Discontinuity and fixed points in fuzzy metric space, J. Fuzzy Math.,16(1)(2008), 43.

[13] Rhoades B E, Contractive definitions and continuity, Contemporary Math., 72(1988), 233.

[14] Sharma S, Common fixed point theorems in fuzzy metric spaces, Fuzzy Sets and Systems, 127(2002), 345.

[15] Sharma S, Pathak A \& Tiwari R, Common fixed point of weakly compatible maps without continuity in fuzzy metric space, Int. J. Appl. Math., 20(4)(2007), 495.

[16] Singh B \& Jain S, Semi-compatible and fixed point theorems in fuzzy metric space, Chungcheong Math. Soc., 18(2005), 1.

[17] Subrahmanyam P V, A common fixed point theorem in fuzzy metric space, Inform. Sci., 83(1995), 103.

[18] Vasuki R, Common fixed points for R-weakly commuting mappings in fuzzy metric spaces, Indian J. Pure and Appl. Math., $30(1999), 419$.

[19] Zadeh L A, Fuzzy sets, Inform. and Control., 89(1965), 338. 